\title{
Consensuar un pacto educativo en contextos de cambio: derecho de cada persona a la educación
}

\author{
Consensus on an educational pact in contexts of change: the right \\ of each person to education
}

\section{Acordar um Pacto Educacional em Contextos de Mudança: O Direito de Toda Pessoa à Educação}

\author{
Cecilia Martins* \\ Organización de los Estados Americanos (OEA) \\ Washington DC, Estados Unidos \\ education@oas.org \\ (1D) https://orcid.org/0000-0002-5121-4629
}

Recibido - Received - Recebido: 04 / 06 / 2021 Aceptado - Accepted - Aprovado: 08 / 06 / 2021

\author{
DOI: https://doi.org/10.22458/ie.v23i24.3586 \\ URL: https://revistas.uned.ac.cr/index.php/innovaciones/article/view/ 3586
}

\begin{abstract}
Resumen: El derecho de cada persona a la educación resulta un elemento trasformador en sí mismo, con el potencial de transformar las vidas de las personas, comunidades y sociedades. Existe una amplia gama de marcos normativos, declaraciones y compromisos firmados y asumidos por los países de la región. Sin embargo, con tan solo mencionar el tema no es suficiente. La necesidad de un compromiso no solo político sino económico y de financiamiento de la educación, para que efectivamente pueda garantizarse el derecho a la continuidad educativa de todas las personas en un marco de educación de calidad, inclusivo y con equidad. En este sentido, también cabe destacar el valor comparativo que constituye la gobernanza y su formidable efecto de incidencia educativa al reforzar la vital importancia de la adopción de un enfoque de derechos, basado en la no discriminación, pero por sobre todas las cosas, enfocado en la igualdad de acceso y permanencia de grupos más vulnerables.
\end{abstract}

Palabras clave: Derecho a la educación; Pacto educativo; Inclusión-no discriminación; Contextos de cambio; Liderazgo

\begin{abstract}
The right of each person to education is a transformative element in itself with the potential to transform the lives of individuals, communities and societies. There is a wide range of regulatory frameworks, declarations and commitments signed and assumed by the countries of the region. However, just mentioning the subject is not enough. The need for a not only political but also economic commitment and the financing of education so that the right to educational continuity of all people can be effectively guaranteed in an inclusive and equitable framework of quality education. In this sense, it is also important to highlight the comparative value that governance constitutes and its formidable educational impact effect by reinforcing the vital importance of adopting a rights-based approach based on non-discrimination, but above all, focused on equal access and permanence of the most vulnerable groups.
\end{abstract}

Keywords: Education rights; Educational pact; Inclusion-Non-discrimination; Contexts of change; Leadership

Resumo: $O$ direito de cada pessoa à educação é um elemento transformador em si mesmo com o potencial de transformar a vida dos indivíduos, comunidades e sociedades. Existe uma ampla gama de estruturas normativas, declarações e compromissos assinados e assumidos pelos países da região. Entretanto, a simples menção da questão não é suficiente. Há necessidade não só de compromisso político, mas também de compromisso econômico e financiamento da educação, a fim de garantir efetivamente o direito à continuidade educacional para todas as pessoas dentro de uma estrutura de educação de qualidade, inclusiva e equitativa. Neste sentido, também é importante destacar o valor comparativo da governança e seu formidável impacto na educação, reforçando a grande importância de adotar uma abordagem baseada em direitos e na não-discriminação, mas, acima de tudo, focada na igualdade de acesso e permanência para os grupos mais vulneráveis.

Palavras chave: Direito à educação; Pacto Educacional; Inclusão-Não-discriminação; Contextos de mudança; Liderança

* Los puntos de vista expresados en este documento no representan necesariamente los de la Secretaría General ni los de la Organización de los Estados Americanos. 
Tanto a nivel global como regional y local la mención de garantizar el derecho de cada persona a la educación, aparece reflejado contundente y sistemáticamente en múltiples documentos, discursos, artículos (como este), espacios de debate, intercambio y construcción colectiva del conocimiento. Existe una amplia gama de marcos normativos, declaraciones y compromisos firmados y asumidos por los países de la región. Sin embargo, tan solo con mencionar el tema no es suficiente. Las cifras y las estadísticas recientes reflejan la cruda realidad.

Nuestra región, las Américas, es la región más desigual del mundo. ¿Qué nos indica este aspecto sobre nuestras prioridades, mecanismos de sostenibilidad financiera de la educación y capacidad de gestión efectiva para lograr el objetivo tan deseado de poner fin a toda forma de discriminación y, en el proceso, garantizar el derecho a la educación para toda persona? ¿Significará quizás que como sociedad, como comunidades en constante cambio y evolución, seguimos "esquivando", evadiendo de una forma u otra un abordaje multidimensional, profundo, consensuado, mediado y referenciado?

Las urgencias -cada vez más evidentes como consecuencia de la pandemia- y las deudas impostergables con las poblaciones más vulnerables, reclaman a viva voz la necesidad de despojarnos como sociedad y comunidad educativa en particular, de personalismos y recetas sobre "experiencias exitosas", para comenzar a andar un camino en donde las miradas complementarias, los tonos inclusivos y las construcciones colectivas sean finalmente una realidad cotidiana.

Hablar de garantizar el derecho a la educación para todas las personas no puede seguir siendo solo un "llamado a la acción", necesita un cambio categórico en términos de respeto y oportunidades, de escucha activa, involucramiento desde cada nivel de gestión y liderazgo, pero por sobre todos los aspectos está pidiendo claro y fuerte desde cada rincón del territorio, un nuevo pacto educativo cuya incidencia pueda multiplicar de modo exponencial los cambios que las nuevas generaciones necesitan y merecen.

\section{DESARROLLO}

La mención a garantizar el derecho de cada persona a la educación, aparece reflejado en múltiples declaraciones, documentos, discursos, artículos, espacios de debate, intercambio y construcción colectiva de conocimiento tanto a nivel global como regional y local. Ya en 1948 la Carta de la Organización de los Estados Americanos (OEA, 1948) resaltaba en su artículo 49, la voluntad de los países de la región en poner en marcha sus mayores esfuerzos para asegurar, de acuerdo con sus normas constitucionales, el ejercicio efectivo del derecho a la educación.

La Carta Democrática Interamericana (OEA, 2001) reconoce asimismo que la promoción y la observancia de los derechos son consustanciales al desarrollo integral, el crecimiento con equidad, la consolidación de la democracia y el estado de derecho en las Américas. En particular, su capítulo 2 artículo 8 expresa que toda persona tiene derecho a la educación sin discriminación, por medio del acceso a una educación de calidad en todos los niveles y modalidades y, por tanto, resulta vital para lograr mayor equidad, mejorar los niveles de vida, fomentar el desarrollo sostenible, desarrollar el capital humano, reducir la pobreza, fortalecer las instituciones democráticas, transmitir valores cívicos y sociales, formar ciudadanos responsables y comprometidos con la sociedad y promover la inclusión social.

Hace apenas un poco más de cinco años, la Declaración de Incheon (UNESCO, 2015) reafirma la educación como un bien público, un derecho humano fundamental para lograr el pleno empleo y la erradicación de la pobreza, con un foco en el acceso, la equidad, la inclusión, la calidad y los resultados del aprendizaje, dentro de un enfoque del aprendizaje a lo largo de toda la vida. Recientemente, el Comité 
de Dirección Regional ODS-E2030 de América Latina y el Caribe, en su Declaración (UNESCO, 2021) enfatiza nuevamente el derecho a la educación como elemento fundamental para el presente y futuro de América Latina y el Caribe.

Todas estas referencias manifiestan alto y claro que la decisión y compromiso político y su marco normativo están, en buena parte, cubiertos. Ahora bien, ¿qué indican los datos y los reportes sobre la situación de la región? ¿Cómo este sólido marco se traduce en acción por medio de las oportunidades que ofrecen los sistemas educativos de la región?

Según datos del Observatorio de la CEPAL (CEPAL, 2018) durante el período 2010-2018 -que de cierta forma expresa en cifras los procesos de transición entre los resultados de los Objetivos de la Agenda 2015 hacia la Agenda 2030 en temas de educación-, se puede observar que el gasto en educación de los gobiernos a nivel central en virtud de su PBI, se ha incrementado en un punto (de 3.1 a 4.0) desde el 2015, punto de partida de la Agenda E2030. Sin embargo, en septiembre de 2020 la UNESCO ha expresado su preocupación por el impacto que la pandemia provocada por el virus responsable de la COVID-19 puede tener en los países más pobres, en los cuales se advierte que el déficit de financiación para alcanzar el ODS4 podría aumentar a 200.000 millones anuales.

Estos y otros análisis indican alarmantemente la necesidad de un compromiso no solo político sino económico y de financiamiento de la educación, para que en efecto pueda garantizarse el derecho a la continuidad educativa de todas las personas en marco de educación de calidad, inclusivo y con equidad. (2017).

Finalmente, el tercer elemento fundamental en esta triada lo constituye la gobernanza y su formidable efecto de incidencia educativa. Gobernanza entendida como el cúmulo de leyes, políticas públicas, prácticas y programas, procedimientos administrativos y de monitoreo y gestión.

Boly Barry (2018), la Relatora Especial sobre la gobernanza y el derecho a la educación en el Informe sobre la gobernanza y el derecho a la educación, refuerza claramente la vital importancia de la adopción de un enfoque de derechos basado en la no discriminación, pero por sobre todas los aspectos, enfocado en la igualdad de acceso y permanencia de grupos más vulnerables.

\section{SINTESIS Y REFLEXIÓN FINALES}

Los altibajos durante estos tiempos de pandemia han visibilizado, no solo las grandes deudas, sino también todo aquello que durante años -como comunidad educativa- nos habían asegurado que no podía hacerse, se hizo.

Las paredes y los muros que marcaban espacios "intocables" se han esfumado permitiendo ver más claramente, cómo en tiempos de cambio la comunidad educativa en todos sus niveles y con todos sus actores ha propiciado ese cambio y sostenido solidariamente la continuidad educativa.

El contexto esta dado para construir desde la adversidad, para generar y mantener ese tiempo de reflexión para la acción, para valorar fortalezas y sumar desde las diferencias y sí, porque no, soñar y hacer realidad un nuevo pacto educativo basado en el derecho a una educación de calidad, inclusiva y con equidad. 


\section{REFERENCIAS}

Boly Barry, K. (2018). Derecho a la Educación Informe de la Relatora Especial sobre gobernanza y derecho a la educación. Recuperado de https://www.right-to-education.org/es/resource/ informe-del-relator-especial-la-gobernanza-y-el-derecho-la-edu

CEPAL. (2018). Base de datos de inversión social en América Latina y el Caribe. Recuperado de https://observatorioso-cial.cepal.org/inversion/es/indicador/gasto-educacion

OEA (1948). Carta de la Organización de los Estados Americanos. Recuperado de http://www.oas.org/ es/sla/ddi/docs/tratados_multilaterales_interamericanos_A-41_carta_OEA.pdf

OEA (2017). Agenda Educativa Interamericana. Reunión Interamericana de Ministros de Educación, Bahamas 2017. Recuperado de http://scm.oas.org/IDMS/Redirectpage.aspx?class=V.12.1\%20CIDI/ $\mathrm{RME} /$ doc.\&classNum $=6 \&$ lang $=\mathrm{s}$

OEA (2001). Carta Democrática de la OEA. Recuperado de http://www.oas.org/OASpage/esp/ Documentos/Carta_Democratica.htm

Regional ODS-E2030 de América Latina y el Caribe (s.f.). Priorizar el derecho a la educación salvará el presente y futuro de América Latina y el Caribe. https://unesdoc.unesco.org/ark:/48223/ pf0000375689

UNESCO (2015). Declaración de Incheon. Educación 2030: Hacia una educación inclusiva y equitativa de calidad y un aprendizaje a lo largo de la vida para todos. Recuperado de http://www.unesco.org/ new/fileadmin/MULTIMEDIA/FIELD/Santiago/pdf/ESP-Marco-de-Accion-E2030-aprobado.pdf

UNESCO (2020). La UNESCO advierte que el déficit de financiación para alcanzar el ODS4 en los países más pobres podría aumentar a 200.000 millones anuales a causa de Covid-19 si no tomamos me $\neg$ didas urgentes. Recuperado de https://es.unesco.org/news/unesco-advierte-que-deficitfinanciacion-alcanzar-ods4-paises-mas-pobres-podria-aumentar-200000

UNESCO. (2021). Comité Regional ODS4. Agenda 2030. Declaración del Comité de Dirección. 